\title{
Ethical and Passive Leadership and Their Joint Relationships with Burnout via Role Clarity and Role Overload
}

\author{
Jesse T. Vullinghs ${ }^{1} \cdot$ Annebel H. B. De Hoogh ${ }^{2}$. Deanne N. Den Hartog ${ }^{2} \cdot$ Corine Boon $^{2}$
}

Received: 26 September 2017 / Accepted: 4 December 2018 / Published online: 11 December 2018

(c) The Author(s) 2018

\begin{abstract}
Burnout has important ramifications for employees and organizations and preventing burnout forms an ethical issue for managers. However, the role of the leader and especially the role of ethical aspects of leadership have received relatively little attention in relation to burnout to date. We conducted a survey among employees $(N=386)$ of a Dutch retail organization, nested in 122 teams with a leader. Our first contribution is that we empirically show the hypothesized opposing relationships of ethical and passive leadership behavior with follower burnout. Furthermore, we examined two job characteristics as mechanisms that link these forms of leadership and burnout. Lastly, we show that the positive relationship of ethical leadership with burnout via role clarity (but not overload) is dependent on the degree of passive leadership the leader is perceived to display. Our results suggest that organizations should promote ethical leadership behaviors and limit passive leadership behaviors by stimulating leaders to be active in their role and use their social influence to promote ethical conduct.
\end{abstract}

Keywords Ethical leadership · Passive leadership $\cdot$ Follower burnout $\cdot$ Job characteristics $\cdot$ Role clarity $\cdot$ Role overload

Burnout, a negative affective response to chronic work stressors (Halbesleben 2006; Maslach 1982), has been linked to cognitive impairment, somatic morbidity, and emotional dysfunctions (Golkar et al. 2014; Johnson and Hall 1988). Employees suffering from burnout report longstanding fatigue, sleep impairments, physical complaints and problems with memory and concentration (Schaufeli et al. 2009). Burnout also has important socio-economic ramifications as it relates to increases in turnover, absenteeism, and reduced productivity at work (Halbesleben and Buckley 2004). Organizations have an ethical obligation to serve the interests of all legitimate stakeholders, including employees (Carroll 1991; Donaldson and Preston 1995), and as such, Guest (2017) states that safeguarding employee well-being is an important ethical concern for managers. Considering this ethical obligation as well as the negative repercussions

Annebel H. B. De Hoogh

a.h.b.dehoogh@uva.nl

1 Management and Organisation, School of Business and Economics, Vrije Universiteit Amsterdam, De Boelelaan 1105, 1081 HV Amsterdam, The Netherlands

2 Leadership and Management, Amsterdam Business School, University of Amsterdam, P.O Box 15953, 1001 NL Amsterdam, The Netherlands of burnout for both employees and organizations alike, the management and prevention of burnout can be seen as a major ethical issue for leaders. Research has identified several organizational risk factors as possible antecedents of burnout, such as role ambiguity and overload, a lack of social support and perceptions of unfairness at work (e.g., Lee and Ashford 1996; Maslach and Leiter 2008). However, the role of ethical aspects of leadership has received relatively little attention in relation to burnout to date.

Although research in this area is scarce, there are a few studies that link ethical leadership, described as a leader's use of social influence to promote ethical conduct (Brown et al. 2005), to emotional exhaustion (Chughtai et al. 2015) and burnout (Mo and Shi 2017). Laissez-faire or passive leadership behavior is often seen as a less ethical form of leadership (Den Hartog 2015; Einarsen et al. 2007), as assigned duties and responsibilities are not being fulfilled by the leader and leaders demonstrate a lack of care. Passive leadership is negatively related to ethical leadership (Kalshoven et al. 2011). Passive leadership is also found negatively related to follower well-being and strain (e.g., Skogstad et al. 2007), but its relationship with burnout is still uncertain (Skakon et al. 2010; Skogstad et al. 2007). Here, we examine the relationship of both ethical and passive 
leadership with employee burnout and in addition address two mayor concerns that require further research.

First, the possible mechanisms through which ethical and passive forms of leadership may influence burnout are not yet sufficiently clear. Previous research has focused on social mechanisms (e.g., team cohesion) through which ethical leadership can affect stress-related outcomes (Mo and Shi 2017; Zheng et al. 2015). Drawing on (ethical) leadership theory (Brown et al. 2005; Den Hartog 2015) and Karasek's demand-control model of job stress $(1979,1998)$, we develop and test a model in which two important job characteristics, namely role clarity and role overload are proposed as mediating variables through which ethical and passive leadership may affect burnout. From a demand-control perspective (Karasek 1979), we argue that ethical leadership reduces strain by providing heightened perceptions of influence and control over work load and lowered perceptions of pressure of demands, whereas passive leadership increases such strain by lowering perceptions of control and heightening perceptions of demands.

Ethical leadership provides role clarity for employees as leaders high on this style model appropriate behavior and provide ethical guidance (Brown et al. 2005; Den Hartog 2015; Kalshoven et al. 2011). In addition, because ethical leadership implies treating followers fairly and with respect and demonstrating care for followers (Brown et al. 2005; De Hoogh and Den Hartog 2009a), ethical leadership is expected to ensure that work is distributed fairly and in ways followers can handle, thereby reducing employees' perceptions of role overload. In line with previous research (Barling and Frone 2017), we expect that passive leadership, which implies being less inclined to take action to prevent or solve problems (DeRue et al. 2011), or help and guide followers when needed (Den Hartog 2015), will neither provide sufficient role clarity, nor try to prevent followers' role overload. Role clarity (relating to control) and role overload (relating to demands) have gained considerable research attention as part of Karasek's demand and control job stress model $(1979,1998)$ and have typically been associated with (aspects of) burnout (Jackson and Schuler 1985; Schaufeli and Bakker 2004). Thus, we expect ethical leadership to be negatively related to burnout via higher experienced role clarity and lower role overload and passive leadership to be positively related to burnout though lower role clarity and higher role overload.

Second, previous research suggests that it may not be accurate to categorize individual leaders as ethical or passive. Instead, every leader displays a variety of behaviors, and it is possible for managers to engage in both ethical and unethical leader behaviors (Lin et al. 2016; Mullen et al. 2011), or as we study here to engage in both ethical and passive leadership behaviors. Yet, little is known about the effects of mixing ethical and passive leadership behaviors.
To address this, the purpose of our study is to empirically examine the effect of both ethical and passive leadership behavior on employee burnout. The non-participation, lack of direction and care, and unresponsiveness of passive leadership contradicts with the consideration and guidance ethical leadership provides (Steinmann et al. 2016). Thus, leaders who are seen to act both in ethical and passive ways display inconsistent leader behaviors and research suggests that behavioral inconsistency hampers the clarity and credibility of the leader actions (Johnsen et al. 2012). Thus, we advance, and empirically test, the hypothesis that perceived passive leader behaviors attenuate the expected negative relationship of perceptions of ethical leadership with burnout via diminished role clarity and increased role overload. Our study thus adds to the literature by looking at ethical aspects of leadership in relation to burnout and by answering recent calls to examine what happens when leaders display a variety of behaviors, including ones that form different and even seemingly inconsistent or opposite types of behavior (Lin et al. 2016; Johnson et al. 2012). Figure 1 depicts the research model. We test our expectations in a sample $(N=386)$ of Dutch office workers of a large retail organization.

\section{Theoretical Background and Hypotheses}

\section{Burnout}

Burnout is a chronic work-related stress syndrome characterized by three main elements: exhaustion, depersonalization, and reduced personal accomplishment (Halbesleben 2006; Maslach 1982; Maslach et al. 2001). Exhaustion is defined as the feeling that one's energy resources are depleted (Maslach and Jackson 1981). Depersonalization, also referred to as cynicism, describes an individual's negative or excessively detached response to various aspects of the job (Maslach et al. 2001). Lastly, reduced personal accomplishment encompasses the self-evaluation aspect of

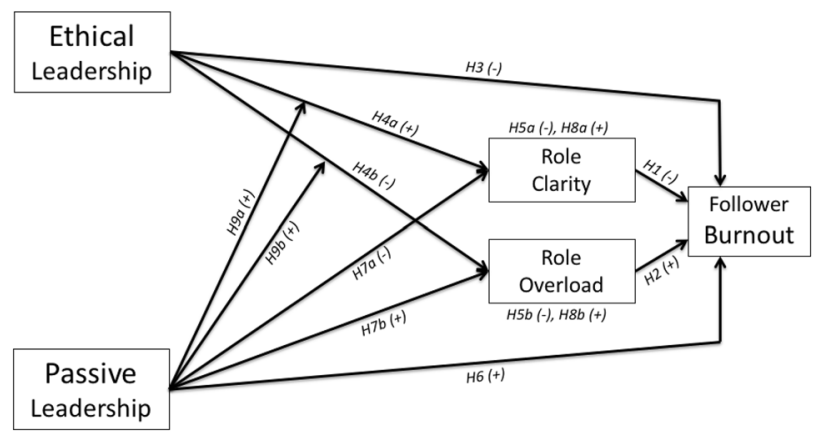

Fig. 1 Theoretical model 
burnout and entails feelings of incompetence and a lack of achievement at work (Maslach et al. 2001).

Burnout has negative consequences for both the individual and the organization. For example, research shows that chronic stress at work results in lower cognitive functioning (Golkar et al. 2014) and increases the chance of cardiovascular disease (Johnson and Hall 1988). Furthermore, chronic stress is shown to have a high comorbidity with other psychological disorders such as anxiety or depression (Holden et al. 2011). Consequently, burnout has great ramifications for the organization, such as increased turnover, absenteeism, and reduced productivity (e.g., Halbesleben and Buckley 2004). Safeguarding employee well-being forms an ethical concern in organizations (e.g., Guest 2017) and given its strong negative impact, the prevention of burnout forms a major ethical issue for management and organizations (Barnett et al. 2007).

Research has identified a variety of organizational risk factors as possible antecedents of burnout. Cordes and Dougherty (1993) propose three categories of antecedents of burnout, namely job and role characteristics, organizational characteristics, and personal characteristics. This categorization is supported by Maslach et al. (2001), who add that personal characteristics show a weaker relationship with burnout compared to the other two categories, which focus on situational factors. Examples of situational factors are job characteristics such as role clarity and role overload at work (e.g., Maslach and Leiter 2008), which have both received considerable research attention in studies addressing the demand-control model (Karasek 1979; Karasek and Theorell 1990). According to the demand-control model, high work demands (here we focus on role overload) and low job control (here we focus on low role clarity) lead to detriments in well-being. Fulfilling high job demands and coping with a lack of role clarity draws heavily on employees' resources, resulting in load reactions (strain, fatigue, and burnout).

Role clarity is defined as the degree to which individuals feel they have clear guidance about expected roles and behaviors associated with their job (Kahn et al. 1964). Role clarity implies that the follower is aware of his or her responsibility, role, and tasks within the organization and team (Rizzo et al. 1970), and that the follower understands what the leader expects of him or her (Kalshoven et al. 2011). Leader behavior thus forms a key driver of experienced role clarity. Role clarity provides employees more job control. In line with Karasek's demand-control model $(1979,1998)$ increased control, in the form of role clarity, should lead to less strain on the employee. On the contrary, a lack of role clarity, also referred to as role ambiguity, results in attempted coping behavior in order to prevent negative outcomes such as stress and anxiety (Kahn et al. 1964). Ironically, such coping behaviors impose additional demands on the employee, which results in additional strain on the employee (Karasek 1979, 1998). Research shows that lack of role clarity is associated with negative follower outcomes and burnout (e.g., Maslach and Jackson 1984; Maslach et al. 2001). Thus, we hypothesize:

Hypothesis 1 Role clarity is negatively related to burnout.

Role overload is characterized by a workload, work demands or a set of responsibilities that exceeds the particular role and capacity of the employee in the time available (Beehr et al. 1976; Bolino and Turnley 2005). Role overload is likely to either arise from demands imposed on the employee by the organization or leader or by the employee him- or herself. In line with role theory, Welbourne and colleagues (1998) propose that employees enact two roles: the job-holder role and the organizational member role. The job-holder role prescribes the formal responsibilities of the employee, whereas the organizational member role entails the individual's expectations to be a good employee. Successfully fulfilling both roles is associated with higher performance appraisal ratings (Allen and Rush 1998), and the drive to excel could motivate employees to impose excessive demands on themselves.

Excessive demands in either of these roles or both, whether imposed by the organization (e.g., through the leader) or the employee him or herself is likely to result in role overload. In turn, experienced role overload is associated with negative follower outcomes, such as lower organizational commitment and increased absenteeism (Duxbury and Higgins 2001; Mulki et al. 2006). Moreover, in line with Karasek's demand-control model $(1979,1998)$, role overload is also consistently found related to burnout since it imposes additional demands on the employee. Past research shows that in particular the exhaustion dimension is related to role overload (Maslach et al. 2001). Thus, we hypothesize:

Hypothesis 2 Role overload is positively related to burnout.

\section{Ethical Leadership and Burnout}

Brown et al. (2005, p. 120) define ethical leadership as "the demonstration of normatively appropriate conduct through personal actions and interpersonal relationships, and the promotion of such conduct to followers through two-way communication, reinforcement, and decisionmaking." Ethical leadership is thus characterized by leaders' demonstration of ethical conduct and refers to using social exchange (Brown et al. 2005), forming a role model (Mayer et al. 2013), and rewarding and punishing with the aim to promote ethical behavior in their followers (Treviño et al. 2003). Ethical leader behavior is concerned with transparency, involving employees in decision-making and 
providing clarity about ethical standards and expectations to followers. Such ethical behaviors on part of leaders enable followers to know what is expected of them in terms of performance goals and responsibilities and to feel more involved (De Hoogh and Den Hartog 2008; Kalshoven et al. 2011). Ethical leadership behaviors include demonstrating integrity and considerate and fair treatment of employees (Brown et al. 2005) as well as people-oriented behaviors such as demonstrating genuine care for followers and their needs (Resick et al. 2006; Treviño et al. 2003). Taken together, when followers perceive such ethical leader behaviors, this will help them experience greater well-being, and less stress and burnout (Siegrist 1996). Indeed, while research on this is still limited, the previous research that is out there has found ethical leadership positively related to follower satisfaction and other indicators of well-being (Den Hartog 2015). Research has also linked ethical leadership to less emotional exhaustion (Chughtai et al. 2015) and burnout (Mo and Shi 2017). Thus, we expect:

Hypothesis 3 Ethical leadership is negatively related to burnout.

The possible mechanisms through which ethical and passive forms of leadership may influence burnout are not yet sufficiently clear. Here, building on the demand-control model (Karasek 1979), we propose that role clarity and overload form two such mechanisms. Ethical leadership is likely to enhance the role clarity that followers experience. Ethical leadership actively guides followers through setting standards, constant feedback, and clarifying duties and expectations as well as ethical norms (Brown et al. 2005; De Hoogh and Den Hartog 2008). This makes followers aware of what is expected of them and what they can expect from others in the team. Indeed, Kalshoven et al. (2011) show that perceived ethical leadership measured with the scale developed by Brown et al. (2005) correlates positively with both leaders' perceived role clarification and their perceived ethical guidance. Furthermore, the fairness they strive for in ethical leadership (Brown et al. 2005) and people orientation component in ethical leadership with the related openness to input and voice (Resick et al. 2006; Treviño et al. 2003) reflects genuine care about, respect and support for followers, and ensures that where possible followers needs are met. Those high on ethical leadership are thus also more likely to actively try to more fairly distribute the workload and to actively attempt to manage potential role overload of followers. In addition, the care and support provided by ethical leadership (Brown et al. 2005; De Hoogh and Den Hartog 2008) may also prevent followers to impose unrealistic demands on themselves that exceed their capacity in the long term. Thus, we hypothesize:
Hypothesis 4 Ethical leadership is (a) positively related to followers' perceived role clarity and (b) negatively related to their role overload.

The guidance that ethical leadership provides, the openness to input and the care and support for followers ensures that followers experience less stress and uncertainty about what their role is or about the expectations that the leader has of them. Drawing on the demand-control theory of stress (Karasek 1979), this heightened feeling of control and lowered pressure of demands improves individuals' coping abilities, resulting in decreased tension and feelings of burnout in response to ethical leadership. Thus, we propose that ethical leadership, at least in part through providing enhanced role clarity and reduced role overload, is associated with lower follower burnout. Therefore, we expect:

Hypothesis 5 The negative relationship between ethical leadership and follower burnout is mediated by (a) role clarity and (b) role overload.

\section{Passive Leadership and Burnout}

Passive leadership is characterized by the absence of leadership behavior and not taking on assigned responsibilities (Skogstad et al. 2007). Passive leader behavior implies minimizing interaction with followers and when engaging in passive leader behaviors, leaders do not attempt to give direction, feedback or support (Buch et al. 2014; Skogstad et al. 2007). By violating legitimate involvement in the organization, passive leader behaviors are likely to be seen as more unethical and uncaring by followers (Einarsen et al. 2007), triggering followers' negative feelings and distress. For example, failing to provide subordinates important information or feedback or failing to support a subordinate when verbally attacked by a customer can be a root cause of long-term role stress (Skogstad et al. 2007). The lack of direction and guidance that passive leadership implies, mean that employees do not know what to expect and are uncertain about their own role and that of co-workers, which may enhance chronic work stress and burnout. Indeed, research by Barling and Frone (2017) found passive leadership related to higher levels of psychological work fatigue and poorer mental health. Taken together, passive leader behavior is expected to contribute to the development of follower burnout. Thus, we hypothesize:

Hypothesis 6 Passive leadership is positively related to burnout.

In contrast with ethical leadership, we argue that showing passive leadership is less likely to provide role clarity. As passive leadership implies being less likely to give direction, 
feedback or reward (Buch et al. 2014; Skogstad et al. 2007), we expect followers who encounter passive leadership to experience higher ambiguity rather than clarity about their role. A lack of role messages or guidance from the superior will create ambiguity concerning goals, responsibilities, influences, and work tasks. Followers are not given relevant information and do not know what is expected of them. Indeed, previous research has demonstrated a positive relationship between passive leadership and role ambiguity (Skogstad et al. 2014; Barling and Frone 2017).

Furthermore, we also expect that passive leadership is less likely to prevent role overload in followers. Leaders perceived as acting passively are less likely to schedule work or actively manage tasks or interpersonal processes. Demands placed on followers by co-workers, clients or customers will less likely be monitored and interventions to minimize excessive demands, or resolve role overload experienced by followers will likely fail to take place (Barling and Frone 2017). Thus, followers are more likely to experience role overload (Buch et al. 2014; Skogstad et al. 2007). Previous research indeed has linked passive leadership to role overload (Barling and Frone 2017). Thus, we hypothesize:

Hypothesis 7 Passive leadership is (a) negatively related to role clarity and (b) positively related to role overload.

As passive leadership is a form of non-leadership, where leaders refrain from taking action to prevent excessive work demands or provide direction for followers (DeRue et al. 2011), this is likely to result in a lack of role clarity and perceptions of role overload. Based on the demand-control theory of stress, which notes that employees feel increased strain as their job demands exceed their perceived ability to cope and they perceive less influence over work (Karasek 1979), this may result in chronic stress and burnout among followers. Thus, we hypothesize:

Hypothesis 8 The positive relationship between passive leadership and follower burnout is mediated by (a) role clarity and (b) role overload.

\section{The Interaction of Passive and Ethical Leadership on Burnout}

Previous leadership research has often used language that tends to describe 'types' of leaders, for example ethical or passive leaders. Such a framing of leadership types suggests that such leaders are always either ethical or passive (Hannah et al. 2014). In line with this view, Walumba and Schaubroeck (2009, p. 1277) state that ethical leadership is by definition constant. However, recent studies are starting to suggest otherwise (Johnson et al. 2012; Lanaj et al. 2016). Leaders do not just engage in one type of leader behavior.
Rather, leaders display a wide variety of behaviors, including ones that seem to be inconsistent or even opposites of a behavioral spectrum, such as ethical and unethical forms leadership. For example, Lin et al. (2016) demonstrated that ethical leadership and abusive supervision can cooccur within the same person. Building on this, we propose this means that leaders may also engage in other seemingly opposing behaviors such as ethical and passive leader behaviors. Passive leader behaviors include avoiding problems, being less dependable, and showing little effort and involvement, which contrasts with the social responsible and caring behavior that is part of ethical leadership (De Hoogh and Den Hartog 2009a). Little, however, is known about what happens when leaders alternately show both ethical and passive leadership.

Here, we address this and examine the effect of both ethical and passive leadership on employee burnout. Employees tend to endorse their leaders more when their behaviors are perceived as consistent. Followers attribute consistent behaviors to stable qualities in leaders and therefore view them as being more genuine and effective (Johnson et al. 2012). Inconsistent behavioral cues (e.g., being principled sometimes and diffusing responsibility at other times) may cause ambiguity and confusion, and may impede positive reactions (Festinger 1957). Inconsistent behavioral cures tend to drain more resources from followers to make sense of their supervisors, which hampers' followers' well-being (Greenbaum et al. 2015). Indeed, research shows that inconsistent abuse from leaders is worse than abuse alone (Thau et al. 2009; Xu et al. 2015). Also, transformational leadership is found to have less positive effects when leaders are also perceived to display passive leader behaviors (Mullen et al. 2011). Duffy et al. (2002) found that a mix of ethical and unethical leader behavior was related to higher levels of insecurity and lower levels of follower trust than consistently unethical leader behavior.

Therefore, we propose that consistent displays of ethical leadership, whereby leaders engage in ethical leadership and refrain from showing passive leader behaviors, will result in increased perceptions of clarity. The ethical guidance provided by the leader and the care expressed will be more credible and less ambiguous when it is not alternated with behaviors reflective of passive leadership, such as instances with a lack of communication or neglecting workplace problems and this will ensure that followers experience more role clarity and less role overload. In contrast, inconsistent displays of ethical leadership, where the leader is seen as being both ethical and passive because he or she alternates between the two leadership styles, will enhance followers' uncertainty about what to expect from their leader and will dampen the leader's credibility (cf. Johnson et al. 2012; Lanaj et al. 2016). For example, combining listening to and discussing ethics and values with employees (ethical 
leader behaviors) with simultaneously making no effort to take necessary actions to solve problems or support follower needs (passive leader behaviors) will undermine leaders' believability. We expect such inconsistency to diminish the positive effects of ethical leadership on role clarity and role overload. Thus, followers will experience less role clarity and more role overload and consequently more burnout when the leader is perceived to engage in ethical but also in passive leadership. Therefore, we hypothesize:

Hypothesis 9 Passive leadership will moderate the negative indirect relationship between ethical leadership and burnout through (a) role clarity and (b) role overload, such that the relationship will be stronger for leaders scoring low on passive leadership compared to leaders who score high on passive leadership.

\section{Methods}

\section{Sample and Procedure}

To test our hypotheses, we collected data via an online survey in a sample of office workers of a large Dutch retail organization. The sample consists of employees of different departments $(N=7)$ and different hierarchical levels within the same organization. Most departments were responsible for dealing with suppliers. The different departments contained up to three hierarchical levels. All managers of these sub-departments at the different levels where identified as leaders in this study (a total of 122 groups participated). Participation of a department was dependent on the top managers' willingness to participate. The incentive of top managers to have their department participate was a report with the anonymized results of the study specific for their department. All employees of the participating departments were invited to participate in the study. Participation of employees was voluntary and was allowed during working hours. The incentive of employees to participate was that anonymized results of the study would be used to improve the working conditions.

The study was announced via an email of the top management to all employees of the participating departments. The privacy and anonymity of the participants were guaranteed by not providing the raw data to the organization and by reporting back only mean scores for the part-taking departments. A week after announcing the study, the researchers sent an email to all employees with instructions, a code that linked the participants to their direct supervisor, and an anonymous link to the online survey. The coding of the supervisors was done by the research group and was not shared with the sample organization to guarantee confidential treatment of the data. The participants rated burnout, job characteristics and the leadership style of their direct supervisors.

A total of $N=386$ completed surveys were returned, yielding a response rate of $68 \%$. In the data 122 groups with one leader were identified (followers per group: mean $=3.2$, $\min =1, \max =10$ ). The average age of the respondents was 40 years, with a minimum of 24 and a maximum of 62 . The sample contains $55 \%$ women and $45 \%$ men.

\section{Description of Measures}

Unless otherwise indicated, participants rated all items on a seven-point Likert scale that ranged from 1 (strongly disagree) to 7 (strongly agree).

\section{Ethical Leadership}

Ethical leadership was assessed with the ten-item Ethical Leadership Scale (ELS: Brown et al. 2005). Example items are "My supervisor sets an example of how to do things the right way in terms of ethics," "My supervisor makes fair and balanced decisions," and "My supervisor defines success not just by results but also the way that they are obtained." Cronbach's alpha is 0.92 .

\section{Passive Leadership}

Passive leadership was assessed with the six-item scale from the Dutch Charismatic Leadership In Organizations questionnaire (CLIO: De Hoogh et al. 2004; De Hoogh and Den Hartog 2009b). Factor analysis showed that the first item of the scale loaded on multiple factors and was therefore not included in subsequent analyses. Example items are "My supervisor avoids taking decisions," "Problems have to be chronic before my supervisor will take action," and "My supervisor avoids getting involved when time consuming issues arise." Cronbach's alpha is 0.87 .

\section{Role Clarity}

Role clarity was assessed with the five-item role clarity scale from the Questionnaire on the Experience and Evaluation of Work (VBBA; Van Veldhoven and Broersen 1999; Van Veldhoven and Meijman 1994). This questionnaire has been widely used in applied scientific research in the Netherlands (e.g., Van Veldhoven et al. 2002). Example items are "I know exactly what I am responsible for and what I am not responsible for at work," "I know exactly what is expected of me on my job," and "I know exactly what has to be done on my job." Cronbach's alpha is 0.86 . 


\section{Role Overload}

Role overload was assessed with the Beehr et al. (1976) three-item scale. Example item is "The amount of work often feels like it is too much for one person," "I am given enough time to do what is expected of me on my job (reversed scoring)," and "the performance standards on my job are too high." The Cronbach's alpha is 0.69.

\section{Burnout}

Follower burnout was assessed with the 16-item Dutch version of the Maslach Burnout Inventory-General Survey (MBI-GS), which is the most widely used scale to measure burnout (Maslach et al. 2001; Schaufeli and Dierendonck 2000). Factor analysis showed that the three theoretical dimensions of exhaustion, depersonalization, and reduced personal accomplishment that compose burnout (Halbesleben 2006; Maslach 1982; Maslach et al. 2001), are also represented in the data. Therefore, we used the weight of these dimensions as represented in the scale in the calculation of the burnout score per participant. Participants rated their own burnout on a seven-point Likert scale that ranged from 1 (never) to 7 (daily). Example items are "I feel emotionally drained from my work," "I have become less enthusiastic about my work," and "In my opinion, I am good at my job (reversed scoring)." Cronbach's alpha is 0.87 .

\section{Control Variables}

We controlled for age in years and gender $($ male $=1$, female $=2$ ) of the follower, as these demographics might influence the followers' coping abilities and response to stressors at the job. The tenure of follower with the leader in months was included as control variable, as this variable might affect the level of familiarity and interaction of the follower with the leader. We also controlled for work hours per week, as this might affect exhaustion and stress, which relate to burnout.

\section{Statistical Analysis}

Due to the hierarchical structure of the data (with individuals nested in groups and departments), we performed multilevel analysis to test all hypotheses, thereby controlling for potential non-independence between observations. Burnout, the dependent variable in our model, shows significant betweengroup variance $(\mathrm{ICC}=0.11$ ) across leader groups, which indicates that multilevel analysis is necessary (Hox 2002). All variables in the model were measured and conceptualized at the individual level (level 1), as we were interested in individual's perceptions of consistent or inconsistent leader behavior and how this affected outcomes, so we tested the model at the individual level, while controlling for the participants being nested in groups (level 2) and departments (level 3). For missing data, we used maximum-likelihood estimation, which uses all available data in the analysis. Studies have shown that this method generally outperforms other methods to deal with missing data (Allison 2003; Kline 2005).

With 39 items in total and a sample size of 353 for the full model (Model III), the indicator-to-sample size ratio was below 10, which was not sufficient to use full structural equation modeling to test our model. So, in order to test the model in an accurate way and still maintain a favorable indicator-to-sample size ratio, we opted for a two-step approach in which we first tested the measurement model, and then used the manifest variables to test the proposed models. To test our hypotheses we ran three models, one multilevel regression and two multilevel path models, using Mplus software. We used multilevel regression to test the direct relationships in model I. Model II was tested using multilevel path analysis because it includes direct as well as indirect relationships in one model. By using multilevel path modeling, we were able to estimate multiple regression equations at the same time. Model III is based on three equations as is suggested by Preacher et al. (2007), of which the first two are the regressions of the mediators on the independent variables, moderator, and interaction terms. The third is the regression of the dependent variable on the independent variables, moderator, interaction terms, and the mediators. This enables us to estimate all equations, whilst controlling for the others.

We report Chi-square statistics and significance for each analysis. We used Hu and Bentler's (1999) fit criteria, including the comparative fit index (CFI), Tucker Lewis index (TLI), root mean squared error of approximation (RMSEA), and standardized root mean square residual (SRMR), as Chi-square significance is also influenced by the sample size and the size of the correlations between the variables (Nye and Drasgow 2011). Hu and Bentler (1999) proposed that well-fitting models have a SRMR below 0.08 and in addition also have either an RMSEA score below 0.06 or CFI score above 0.95 , or both.

\section{Results}

\section{Measurement Model}

We tested a measurement model at the item level in order to verify whether the scale items measured the five underlying constructs. Our measurement model contained five latent factors (i.e., Ethical leadership, Passive leadership, Role Clarity, Role Overload, and Burnout), of which the burnout factor contained the three lower order factors that 
are inherent to its theoretical definition. The tested model showed acceptable fit $\left(\chi^{2}(689)=1609.411, p<0.001\right.$; $\mathrm{CFI}=0.88 ; \mathrm{TLI}=0.87 ; \mathrm{RMSEA}=0.06 ; \mathrm{SRMR}=0.07$ ) (cf. Hu and Bentler 1999).

Alternative models with fewer factors, such as a model with four factors, combining ethical and passive leadership in one factor, a four-factor model with role overload and burnout combined, and a model with three factors (i.e., Leadership, Job Characteristics, and Burnout) fitted the data worse $\left(\chi^{2}(693)=2232.369, p<0.001\right.$; $\mathrm{CFI}=0.80 ; \mathrm{TLI}=0.79 ; \mathrm{RMSEA}=0.08 ; \mathrm{SRMR}=0.08$, $\chi^{2}(693)=2461.334, p<0.001 ; \mathrm{CFI}=0.77 ; \mathrm{TLI}=0.76$; RMSEA $=0.08$; SRMR $=0.08$, and $\chi^{2}(696)=2389.423$, $p<0.001 ; \mathrm{CFI}=0.78 ; \mathrm{TLI}=0.77 ; \mathrm{RMSEA}=0.08$; SRMR $=0.08)$. We assessed the presence of common method variance in our model by performing Harman's one-factor test. Of the single factor model, none of the fit criteria were met $\left(\chi^{2}(702)=4934.581, p<0.001\right.$; $\mathrm{CFI}=0.45 ; \mathrm{TLI}=0.42 ; \mathrm{RMSEA}=0.13 ; \mathrm{SRMR}=0.12$ ) and the single factor model showed a worse fit to the data compared to the hypothesized model (see Table 1).

\section{Descriptive Statistics}

Descriptive statistics and correlations are shown in Table 2. Ethical leadership correlated negatively with follower burnout $(r=-0.39, p<0.001)$ and passive leadership correlated positively with follower burnout $(r=0.25, p<0.001)$. Consistent with previous studies (e.g., Maslach et al. 2001), the job characteristics role clarity correlated negatively $(r=-0.47, p<0.001)$ and role overload positively $(r=0.28$, $p<0.001)$ with follower burnout. Ethical and passive leadership correlated negatively $(r=-0.46, p<0.001)$.

\section{Model I: Ethical and Passive Leadership with Follower Burnout}

To test our theoretical model as depicted in Fig. 1, we analyzed three multilevel models. The first model is a multilevel regression model to test Hypotheses 3 and 6 and the results are presented in Table 3. All effects were modeled at the within-group level. Based on the statistics proposed by $\mathrm{Hu}$ and Bentler (1999), the first model was just identified $\left(\chi^{2}(8)=3.431\right.$, n.s.; $\mathrm{CFI}=1.00 ; \mathrm{TLI}=1.00 ; \mathrm{RMSEA}=0.00$; $\left.\mathrm{SRMR}_{\text {within level }}=0.02, \mathrm{SRMR}_{\text {between level }}=0.00\right)$. We found a

Table 1 Overview of alternative measurement models

\begin{tabular}{|c|c|c|c|c|c|c|c|c|}
\hline Model & Model description & $\chi^{2}$ & $D f$ & $\Delta \chi^{2}$ & CFI & TLI & RMSEA & SRMR \\
\hline Hypothesized model & & $1609.411^{* *}$ & 689 & & 0.88 & 0.87 & 0.06 & 0.07 \\
\hline Alternative 1 & $\begin{array}{l}\text { Four factors: leadership, role clarity, role overload, and } \\
\text { burnout }\end{array}$ & $2232.369 * *$ & 693 & $622.958 * *$ & 0.80 & 0.79 & 0.08 & 0.08 \\
\hline Alternative 2 & $\begin{array}{l}\text { Four factors: ethical leadership, passive leadership, role } \\
\text { clarity, and role overload/ burnout combined }\end{array}$ & $2461.334 * *$ & 693 & $851.923 * *$ & 0.77 & 0.76 & 0.08 & 0.08 \\
\hline Alternative 3 & Three factors: leadership, job characteristics, and burnout & $2389.423^{* *}$ & 696 & $780.012 * *$ & 0.78 & 0.77 & 0.08 & 0.08 \\
\hline
\end{tabular}

$C F I$ comparative fit index, RMSEA root mean square error of approximation, SRMR standardized root mean square residual $* * p<0.01$

Table 2 Descriptive Statistics and Correlations of Study Variables

\begin{tabular}{|c|c|c|c|c|c|c|c|c|c|c|}
\hline & $M$ & SD & 1 & 2 & 3 & 4 & 5 & 6 & 7 & 8 \\
\hline Ethical leadership & 5.09 & 1.03 & $(0.92)$ & & & & & & & \\
\hline Passive leadership & 3.02 & 1.27 & $-0.46^{* * *}$ & $(0.87)$ & & & & & & \\
\hline Role clarity & 4.75 & 1.16 & $0.40 * * *$ & $-0.31 * * *$ & $(0.86)$ & & & & & \\
\hline Role overload & 4.20 & 1.36 & $-0.14 * *$ & $0.19 * * *$ & $-0.27 * * *$ & $(0.69)$ & & & & \\
\hline Follower burnout & 2.77 & 0.90 & $-0.39 * * *$ & $0.25 * * *$ & $-0.47 * * *$ & $0.28 * * *$ & $(0.87)$ & & & \\
\hline Age follower & 39.61 & 9.06 & 0.00 & 0.05 & $0.13^{* *}$ & -0.03 & -0.08 & - & & \\
\hline Gender follower & 1.55 & 0.50 & -0.03 & 0.01 & 0.01 & 0.08 & -0.02 & $-0.11 *$ & - & \\
\hline Tenure & 18.34 & 19.69 & $-0.10^{*}$ & 0.01 & $0.14 * *$ & -0.08 & 0.03 & 0.09 & -0.03 & - \\
\hline Work hours & 37.62 & 4.65 & 0.05 & -0.05 & 0.03 & $-0.11 *$ & -0.09 & $-0.10^{*}$ & $-0.35 * * *$ & -0.01 \\
\hline
\end{tabular}

Within-level correlations are presented. $N=330$ due to missing values, using listwise deletion. Alphas are in parentheses. Age is measured in years. Men are coded 1 and women are coded 2 . Tenure with leader is measured in months

$* p<0.05, * * p<0.01, * * * p<0.001$ All tests are one-tailed 
Table 3 Results of multilevel regression of direct effects

\begin{tabular}{lcll}
\hline Variable & \multicolumn{3}{l}{ Burnout } \\
\cline { 2 - 4 } & Coefficient & $S E$ & $R^{2}$ \\
\hline Constant & $4.03^{* * *}$ & 0.32 & $0.17^{* * * *}$ \\
Ethical leadership & $-0.31^{* * *}$ & 0.05 & \\
Passive leadership & 0.08 & 0.05 & \\
Age follower & -0.01 & 0.01 & \\
Gender follower & $-0.13^{*}$ & 0.06 & \\
Tenure with leader & 0.00 & 0.00 & \\
Work hours & -0.02 & 0.01 & \\
\hline
\end{tabular}

Unstandardized coefficients are presented. Age is measured in years. Men are coded 1 and women are coded 2. Tenure with leader is measured in months. Work hours are measured as contract hours per week. $N=366$

$* p<0.05, * * * p<0.001$

significant negative relationship between ethical leadership with follower burnout $(\beta=-0.31, p<.001)$ thereby supporting Hypothesis 3. In Hypothesis 6 we suggested a positive relationship between passive leadership and follower burnout, which was not supported by the data $(\beta=0.08, n . s$.).

\section{Model II: The Role of Role Clarity and Role Overload}

In the second model, we performed multilevel path analysis to test Hypotheses 1, 2, 4, 5, 7 and 8, which address the role of role overload and role clarity in the relationships of ethical and passive leadership with burnout. Results of model II are presented in Table 4. Again, all effects were modeled at the within group level. The hypothesized model was just identified $\left(\chi^{2}(8)=3.438\right.$, n.s.; CFI $=1.00$; $\mathrm{TLI}=1.00 ; \mathrm{RMSEA}=0.00 ; \mathrm{SRMR}_{\text {within level }}=0.02$,
$\left.\mathrm{SRMR}_{\text {between level }}=.00\right)$. We should note, however, that while the explained variance of role clarity and burnout are significant, the explained variance of role overload in the model is not significant; thus leadership may only be a small contributor in explaining role overload.

Consistent with previous research we found support for Hypotheses 1 and 2, which stated that role clarity relates negatively $(\beta=-0.27, p<0.001)$, and role overload positively $(\beta=0.10, p<0.001)$ with follower burnout. Furthermore, we found that ethical leadership relates positively to role clarity $(\beta=0.37, p<0.001)$ and negatively to role overload $(\beta=-0.08, p<0.001)$, supporting Hypotheses $4 \mathrm{a}$ and b. In addition, the indirect relationship between ethical leadership and burnout, mediated by role clarity was significant $(\beta=-0.10, p<0.001)$, supporting Hypothesis 5a. Also, the indirect relationship between ethical leadership and burnout, mediated by role overload was significant $(\beta=-0.01$, $p<0.01$ ), supporting Hypothesis 5b. The direct relationship between ethical leadership and follower burnout was also significant in this model $(\beta=-0.19, p<0.001)$, suggesting partial mediation.

With respect to passive leadership, we hypothesized that its relationship with follower burnout is mediated by role clarity (Hypothesis 8a) and role overload (Hypothesis 8b). In line with Hypotheses $7 \mathrm{a}$ and $\mathrm{b}$ respectively, the results showed that passive leadership related negatively to role clarity $(\beta=-0.22, p<0.05)$ and positively to role overload $(\beta=0.21, p<0.05)$. Furthermore, the indirect relationship between passive leadership and burnout, mediated by role clarity was significant $(\beta=0.06, p<0.05)$, supporting Hypothesis $8 \mathrm{a}$. Also, the indirect relationship between passive leadership and follower burnout, mediated by role overload was significant $(\beta=0.02, p<0.05)$, supporting Hypothesis $8 \mathrm{~b}$. The direct relationship between passive leadership
Table 4 Results of multilevel path analysis testing mediation

\begin{tabular}{|c|c|c|c|c|c|c|}
\hline \multirow[t]{2}{*}{ Variable } & \multicolumn{2}{|l|}{ Role clarity } & \multicolumn{2}{|c|}{ Role overload } & \multicolumn{2}{|l|}{ Burnout } \\
\hline & Coefficient & $S E$ & Coefficient & $S E$ & Coefficient & $S E$ \\
\hline Constant & $3.63 * * *$ & 0.93 & $5.59 * * *$ & 0.82 & $4.42 * * *$ & 0.37 \\
\hline Ethical Leadership & $0.37 * * *$ & 0.09 & $-0.08 * * *$ & 0.03 & $-0.19 * * *$ & 0.05 \\
\hline Passive leadership & $-0.22 *$ & 0.08 & $0.21 *$ & 0.09 & 0.02 & 0.04 \\
\hline Age follower & 0.01 & 0.01 & -0.01 & 0.01 & -0.01 & 0.01 \\
\hline Gender follower & 0.11 & 0.15 & 0.13 & 0.12 & -0.10 & 0.05 \\
\hline Tenure with leader & $0.01 * *$ & 0.00 & -0.01 & 0.01 & $0.00 * *$ & 0.00 \\
\hline Work hours & 0.01 & 0.01 & -0.03 & 0.02 & -0.02 & 0.01 \\
\hline Role clarity & & & & & $-0.27 * * *$ & 0.04 \\
\hline Role overload & & & & & $0.10 * * *$ & 0.03 \\
\hline$R^{2}$ & $0.22 * * *$ & & 0.06 & & $0.31 * * *$ & \\
\hline
\end{tabular}

Unstandardized coefficients are presented. Age is measured in years. Men are coded 1 and women are coded 2. Tenure with leader is measured in months. Work hours are measured as contract hours per week. $N=366$

${ }^{*} p<0.05, * * p<0.01, * * * p<0.001$ 
and burnout was not significant in this model $(\beta=0.02, n s)$, which suggests that the relationship is fully mediated by role clarity and role overload.

\section{Model III: The Interaction Between Passive and Ethical Leadership}

To assess the interaction effect of passive and ethical leadership on the previously discussed relationships and test Hypotheses 9a and 9b, we performed multilevel path analysis. All effects were modeled at the within group level. We estimated three equations simultaneously in MPlus. The first two were the regressions of both job characteristics on the two leadership styles and the interaction term (Ethical leadership $\mathrm{x}$ Passive leadership). The third equation was the regression of follower burnout on the leadership styles, the interaction term, and the two job characteristics. Both independent variables were standardized before creating the interaction term. The hypothesized model is just identified $\left(\chi^{2}(0)=0.00\right.$, n.s; CFI $=1.0 ; \mathrm{TLI}=1.00 ; \mathrm{RMSEA}=0.00$; $\left.\mathrm{SRMR}_{\text {within level }}=0.00, \mathrm{SRMR}_{\text {between level }}=0.00\right)$. The results of model III are presented in Table 5.

The results showed a significant moderation of passive leadership on the relationship of ethical leadership with role clarity $(\beta=-0.11, p<0.01)$, supporting Hypothesis 9a. The relationship between ethical leadership and role clarity is stronger when leaders score low on passive leadership, which is depicted in Fig. 2. The results did not provide support for Hypothesis 9b; thus, we did not find this interaction for role overload.

To further assess the significant moderation effect, and in line with the work of Edwards and Lambert (2007) and

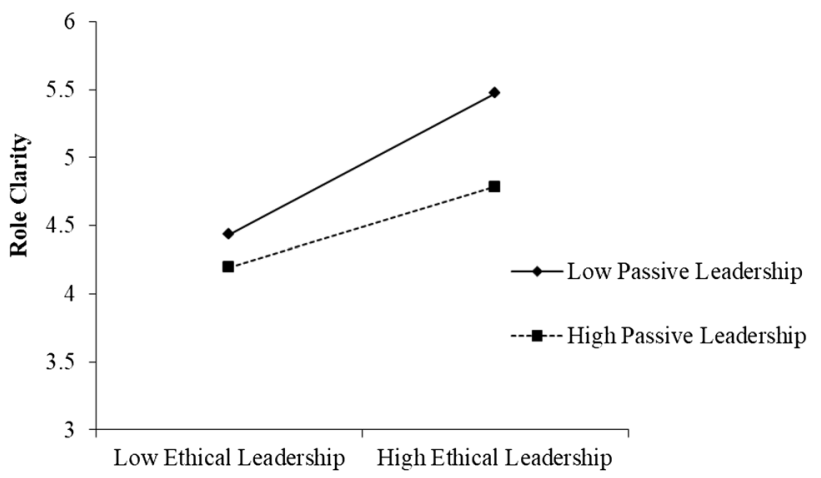

Fig. 2 Moderation effect of passive leadership on the relationship of ethical leadership with role clarity

Preacher et al. (2007), we estimated conditional coefficients (i.e., simple slopes). The results are presented in Table 6 and display the first stage (path from ethical leadership to role clarity), the second stage (path from role clarity to follower burnout) and the indirect effects across different levels of passive leadership. The results show that for leaders low on passive leadership, there is a stronger negative relationship between ethical leadership and follower burnout, mediated by role clarity, than for high passive leadership $(-2 S D$ : $\mathrm{B}=-0.17, p<0.001 ;-1 S D$ : $\mathrm{B}=-0.14, p<0.001 ;$ Mean: $\mathrm{B}=-0.11, p<0.001 ;+1$ $S D: \mathrm{B}=-0.08, p<0.01 ;-1 S D: \mathrm{B}=-0.05, n . s$.$) . These$ results provide further support for Hypothesis $9 \mathrm{a}$, which stated that there is a moderation effect of passive leadership on the indirect relationship of ethical leadership with follower burnout, mediated by role clarity.
Table 5 Results of multilevel path analysis testing moderated mediation

\begin{tabular}{|c|c|c|c|c|c|c|}
\hline \multirow[t]{2}{*}{ Variable } & \multicolumn{2}{|l|}{ Role clarity } & \multicolumn{2}{|c|}{ Role overload } & \multicolumn{2}{|l|}{ Burnout } \\
\hline & Coefficient & $S E$ & Coefficient & $S E$ & Coefficient & $S E$ \\
\hline Constant & $3.42 * * *$ & 0.82 & $5.47 * * *$ & 0.81 & $4.46 * * *$ & 0.39 \\
\hline Ethical leadership & $0.41 * * *$ & 0.09 & $-0.08 * * *$ & 0.02 & $-0.19 * * *$ & 0.06 \\
\hline Passive leadership & $-0.23 * *$ & 0.08 & $0.21 *$ & 0.10 & 0.01 & 0.03 \\
\hline $\begin{array}{l}\text { Ethical leadership } \times \text { pas- } \\
\text { sive leadership }\end{array}$ & $-0.11 * *$ & 0.04 & -0.02 & 0.07 & -0.03 & 0.05 \\
\hline Age follower & $0.02 *$ & 0.01 & -0.01 & 0.01 & -0.01 & 0.00 \\
\hline Gender follower & 0.11 & 0.18 & 0.14 & 0.11 & $-0.12^{*}$ & 0.05 \\
\hline Tenure with leader & $0.01 * * *$ & 0.00 & -0.01 & 0.01 & $0.00 * * *$ & 0.00 \\
\hline Work hours & 0.01 & 0.01 & -0.03 & 0.02 & -0.02 & 0.01 \\
\hline Role clarity & & & & & $-0.26 * * *$ & 0.04 \\
\hline Role overload & & & & & $0.11 * * *$ & 0.03 \\
\hline$R^{2}$ & $0.24 * * *$ & & 0.07 & & $0.32 * * *$ & \\
\hline
\end{tabular}

Unstandardized coefficients are presented. Age is measured in years. Men are coded 1 and women are coded 2. Tenure with leader is measured in months. Work hours are measured as contract hours per week. $N=353$

${ }^{*} p<0.05,{ }^{*} p p<0.01, * * * p<0.001$ 
Table 6 Analyses of simple slopes for follower burnout

\begin{tabular}{|c|c|c|c|c|}
\hline \multirow[t]{2}{*}{ Moderator } & \multirow[t]{2}{*}{ Value } & \multicolumn{2}{|l|}{ Stage } & \multirow{2}{*}{$\begin{array}{l}\text { Effect } \\
\text { Indirect }\end{array}$} \\
\hline & & First & Second & \\
\hline \multirow[t]{5}{*}{ Passive leadership } & $-2 \mathrm{SD}$ & $0.63 * * *(0.13)$ & $-0.26 * * *(0.04)$ & $-0.17 * * *(0.05)$ \\
\hline & $-1 \mathrm{SD}$ & $0.52 * * *(0.10)$ & $-0.26 * * *(0.04)$ & $-0.14 * * *(0.04)$ \\
\hline & Mean & $0.41 * * *(0.09)$ & $-0.26 * * *(0.04)$ & $-0.11 * * *(0.03)$ \\
\hline & $+1 \mathrm{SD}$ & $0.29 * *(0.09)$ & $-0.26 * * *(0.04)$ & $-0.08 * *(0.03)$ \\
\hline & $+2 \mathrm{SD}$ & $0.18(0.12)$ & $-0.26 * * *(0.04)$ & $-0.05(0.03)$ \\
\hline
\end{tabular}

Unstandardized coefficients are presented, standard errors in parentheses. First stage: path from Ethical Leadership to Role Clarity. Second Stage: path from Role Clarity to Follower Burnout. $N=353$

$* * p<0.01, * * * p<0.001$

\section{Discussion}

There is a strong ethical case for focusing on how management practices including leadership affect employee wellbeing (e.g., Guest 2017), and related to this, in this study we set out to examine the relationship of both ethical leadership and passive leadership with burnout. As hypothesized, we found a negative relationship of ethical and a positive relationship of passive leadership with follower burnout. Building on a demands-control perspective (Karasek 1979), we examined role clarity and role overload as potential mechanisms for the relationship between ethical and passive leadership and burnout and indeed found that both relationships are mediated by role clarity and role overload. This mediation was partial for ethical and full for passive leadership. Lastly, we also examined the effects of perceived mixed leader behaviors by assessing how ethical and passive leadership are jointly related to burnout. The results showed a moderating effect of passive leadership on the indirect relationship between ethical leadership and follower burnout, mediated by role clarity, such that leaders who score high on ethical and passive leadership were perceived to provide less role clarity compared to leaders who score high on ethical and low on passive leadership. Role overload was not found to mediate the moderating effect of passive leadership on the relationship between ethical leadership and burnout.

\section{Theoretical Contributions}

This study makes several contributions to the literature. First, we advance the literature by providing (further) evidence for the role of ethical and passive leadership behaviors in relation to follower burnout. Although the positive effect of ethical leadership on follower well-being has been theorized (e.g., Den Hartog 2015), only few studies have empirically assessed this relationship (e.g., Chughtai et al. 2015). The negative association between ethical leadership and follower burnout that we found is consistent with the limited previous work that is available (Mo and Shi 2017). Empirical research on passive leadership and its consequences to date is even more scarce (Eisenbeiss and Brodbeck 2014). Our findings regarding the positive indirect relationship between passive leadership and burnout are new to the literature and add to previous research that suggests the destructive nature of passive leadership (Skogstad et al. 2007). The negative relationship between passive and ethical leadership also supports the notion that passive leadership can be regarded as an unethical form of leadership (e.g., Den Hartog 2015).

Our second contribution is that we examined two job characteristics that link ethical and passive leadership with burnout, thereby providing insight in the mechanisms that relate these forms of leadership with follower burnout, and expanding the demand-control model by considering the role of leadership. Ethical and passive leadership have a seemingly contrasting impact on role clarity and overload. Providing role clarity has been proposed to be important for ethical leadership (e.g., De Hoogh and Den Hartog 2008) and our results empirically support that ethical leadership indeed relates closely to role clarity. Furthermore, ethical leadership is people oriented (Resick et al. 2006; Treviño et al. 2003) and De Hoogh and Den Hartog (2009a) note that the responsible power use inherent in ethical leadership also has the connotation of being aware of the consequences of actions for others, as in 'being responsible for' someone (Den Hartog 2015; Winter 1991). Such leadership entails demonstrating a concern for followers and implies being more likely to pay attention to and manage role overload and reduce unreasonable demands on followers. In contrast, the relationships of passive leadership with the job characteristics support the expected laissez faire nature of passive leadership. The relative lack of care and guidance implied in this form of leading seems to enhance role ambiguity and experienced overload. Interestingly, whereas ethical leadership was found to have both direct and indirect relationships with burnout, the negative effects of passive leadership were found to be only indirect. Thus, passive leadership is related to burnout to the extent that it is associated with role ambiguity and role overload experienced by followers. Taken together, these findings provide new empirical insight on the mechanisms that relate ethical and passive leadership with follower burnout. 
Third, we show that the positive effects of ethical leadership behavior in relation to role clarity are dependent on the degree of passive leadership behavior shown by that same leader. Specifically, our results show that leaders who are perceived to be high on ethical leadership and who are also perceived to display passive leader behaviors provide less role clarity to their followers compared to leaders who are perceived to be high on ethical, but low on passive leadership. We, however, did not find a diminished effect of ethical leadership on burnout via role overload. The perceived inconsistency of a leader displaying both ethical and passive leadership seems to especially bring uncertainty with regard to what is expected of the follower and the direction of their tasks and responsibilities (lowering role clarity). However, perceptions of role overload seem less affected by such inconsistency. Together with the much lower correlations of both leadership styles with role overload than with role clarity, this suggests that other factors in the organization or person may be more important than leader behavior in determining feelings of role overload. Our findings with regard to role clarity do however illustrate that although ethical leadership can be regarded as a positive form of leadership, its positive effects are partially dependent on other behaviors that a given leader shows, including passive ones. It also generally provides further evidence that inconsistency in displays of ethical leadership may have important effects on followers' perceptions of their jobs, work attitudes (cf. Duffy et al. 2002), and chronic work stress and suggests further work on such inconsistency is warranted.

Fourth, as noted we show that Karasek's model (1979) can be expanded by including leader behaviors as potential sources of or as buffers against work stress. Our findings suggest that ethical leadership may reduce strain by providing heightened perceptions of control over work load and lowered perceptions of pressure of demands, whereas passive leadership increases such strain by lowering perceptions of control and heightening perceptions of demands. Also, an inconsistent mix of ethical and passive leader behaviors seems to have a negative impact on perceptions of control and burnout. Our work thus stresses the importance of examining multiple leader behaviors simultaneously in the context of the demand control model to predict job strain and burnout, going beyond previous work based on this model which focused mostly on the role of leaders' supporting behaviors.

\section{Limitations and Directions for Future Research}

This study has some limitations. First, while we collected data in a large sample of employees, we only collected follower ratings of leadership and outcomes. For cross-validation purposes, future studies should aim to use data of multiple sources. Also, our study is cross sectional in nature. However, burnout is a construct that develops over time and therefore it would be interesting to study the relationship between ethical and unethical forms of leadership with follower burnout in a longitudinal study. Moreover, such a study design would enable researchers to draw causal inferences between leadership style and follower burnout, which would greatly advance research on the topic. In addition, the sample was too small to test a full structural equation model. Future research could test the proposed model in a larger sample and use full structural equation modeling to account for measurement error. Next, the CFI and TLI values of the measurement model were slightly below the recommended cutoff value of 0.90 (cf. Hu and Bentler 1999), which is likely due to the relatively low correlations between the variables.

Although we found full mediation of role clarity and overload in the relationship between passive leadership and burnout, we found partial mediation for ethical leadership, which suggests that there are additional mediators for this relationship (e.g., Mo and Shi 2017; Zheng et al. 2015). Examples might be the good and supportive social relationship between leaders perceived as showing ethical behaviors and their followers or the psychological safety the leaders provide. Future studies could look into this, which would further advance our understanding of the mechanisms through which ethical leadership operates. Also, while the results are strong for role clarity, which is clearly related to ethical and passive behavior of leaders, for role overload these leader behaviors did not show strong relationships and while the results of the model can still be interpreted, due to these weak effects our results show that the overall explained variance of role overload in the model is not significant, which suggests that there may be other variables that relate to role overload which we did not include in our model.

Future research could also aim to further differentiate the effects of mixed or inconsistent leader behaviors on followers. For ethical leadership the degree to which the leader is perceived to also display passive leadership seems to play a role, especially in lowering role clarity. However, we did not find a similar impact for role overload and more work on how ethical and passive leadership jointly affect followers seems of interest. Also, certain combinations of ethical and passive leadership may not coexist. If a leader is perceived to enact extreme forms of passive leader behavior, to what extent is it possible for the same leader to also enact high ethical leader behaviors? Extreme perceptions of ethical leadership may require the absence of passive leadership. Future research on the inconsistent displays of ethical and passive leadership is therefore warranted. 


\section{Practical Implications}

Our study also has several practical implications, which are important given the moral obligation organizations have to safeguard employee well-being. For example, our study suggests that ethical conduct of leaders relates to less burnout and thus stimulating ethical leadership is important. Previous research suggests that ethical leadership in organizations can be enhanced through selection and training (Brown and Treviño 2006). Moreover, passive leader behavior is indirectly related to higher burnout. So, organizations should also be attentive to passive leadership as followers may perceive passive leader behaviors as unethical. Organizations could for example train and motivate leaders to be active in their role, by taking on their responsibilities, interacting with followers, and giving followers direction, feedback and support.

Our results also suggest that the positive effects of ethical leadership are partially dependent on other behaviors of that same leader. More specifically, passive leader behaviors can diminish the effects of ethical leader behaviors. When leaders show both ethical and passive leader behaviors, such inconsistent behaviors can be problematic for followers as they are associated with decreased role clarity and increased burnout. Thus, organizations could motivate leaders to be active in their role and consistently show ethical leader behaviors, and to not mix these with passive leader behaviors. In addition, given the importance we found for the job characteristics of role clarity and overload, training leaders how to provide more clarity and be attentive to overload, will also be beneficial in reducing follower burnout. Also, as noted, the relationships of both leader behaviors jointly seem stronger for role clarity than for overload, thus such initiatives are particularly likely to enhance followers' role clarity, and in turn, decrease burnout.

\section{Conclusion}

In conclusion, this study advances our understanding of how ethical and passive leadership relate to follower burnout. Our findings show that ethical leadership is both directly and indirectly associated with lower follower burnout, whereas passive leadership is indirectly related to higher follower burnout. Furthermore, we show that role clarity and role overload are mediators of these relationships and that they potentially form the mechanisms through which these leadership styles affect follower burnout. Lastly, we show that the relationship of ethical leadership with follower burnout via role clarity differs depending on the degree to which the leader is perceived to also display passive leadership. These results suggest that an inconsistent mix of ethical and unethical behaviors can have a negative impact on role clarity and burnout.

\section{Compliance with Ethical Standards}

Conflict of interest The authors declare that they have no conflict of interest.

Open Access This article is distributed under the terms of the Creative Commons Attribution 4.0 International License (http://creativeco mmons.org/licenses/by/4.0/), which permits unrestricted use, distribution, and reproduction in any medium, provided you give appropriate credit to the original author(s) and the source, provide a link to the Creative Commons license, and indicate if changes were made.

\section{References}

Allen, T. D., \& Rush, M. C. (1998). The effects of organizational citizenship behavior on performance judgments: A field study and a laboratory experiment. Journal of Applied Psychology, 83(2), 247-260.

Allison, P. D. (2003). Missing data techniques for structural equation modeling. Journal of Abnormal Psychology, 112(4), 545.

Barling, J., \& Frone, M. R. (2017). If only my leader would just do something! Passive leadership undermines employee well-being through role stressors and psychological resource depletion. Stress and Health, 33(3), 211-222.

Barnett, J. E., Barnett, J. E., Baker, E. K., Elman, N. S., \& Schoener, G. R. (2007). In Pursuit of Wellness: The Self-Care Imperative. Professional Psychology: Research and Practice, 38, 603-612.

Beehr, T. A., Walsh, J. T., \& Taber, T. D. (1976). Relationship of stress to individually and organizationally valued states: Higher order needs as a moderator. Journal of Applied Psychology, 61(7), $41-47$.

Bolino, M. C., \& Turnley, W. H. (2005). The personal costs of citizenship behavior: The relationship between individual initiative and roel overload, job stress, and work-family conflict. Journal of Applied Psychology, 90(4), 740-748.

Brown, M. E., \& Treviño, L. K. (2006). Ethical leadership: A review and future directions. The Leadership Quarterly, 17(6), 595-616.

Brown, M. E., Treviño, L. K., \& Harrison, D. A. (2005). Ethical leadership: A social learning perspective for construct development and testing. Organizational Behavior and Human Decision Processes, 97, 117-134.

Buch, R., Martinsen, O. L., \& Kuvaas, B. (2014). The destructiveness of laissez-faire leadership behavior: The mediating role of economic leader-member exchange relationships. Journal of Leadership \& Organizational Studies, 22(1), 115-124.

Carroll, A. B. (1991). The pyramid of corporate social responsibility: Toward the moral management of organizational stakeholders. Business Horizons, 34(4), 39-48.

Chughtai, A., Byrne, M., \& Flood, B. (2015). Linking ethical leadership to employee well-being: The role of trust in supervisor. Journal of Business Ethics, 128, 653-663.

Cordes, C. L., \& Dougherty, T. W. (1993). A review and an integration of research on job burnout. Academy of Management Review, 18(4), 621-656.

De Hoogh, A. H. B., \& Den Hartog, D. N. (2008). Ethical and despotic leadership, relationships with leader's social responsibility, top 
management team effectiveness and subordinates' optimism: A multi-method study. The Leadership Quarterly, 19, 297-311.

De Hoogh, A. H. B., \& Den Hartog, D. N. (2009a). Ethical leadership: The positive and responsible use of power. In D. Tjosvold $\&$ B. Wisse (Eds.), Power and interdependence in organizations (pp. 338-354). Cambridge: Cambridge University Press.

De Hoogh, A. H. B., \& Den Hartog, D. N. (2009b). Neuroticism and locus of control as moderators of the relationships of charismatic and autocratic leadership with burnout. Journal of Applied Psychology, 94(4), 1058-1067.

De Hoogh, A. H. B., Den Hartog, D. N., \& Koopman, P. L. (2004). The development of the CLIO: A questionaire for measuring Charismatic Leadership in Organisations. Gedrag \& Organisatie, 100, 354-382.

Den Hartog, D. N. (2015). Ethical leadership. Annual Review of Organizational Psychology and Organizational Behavior, 2, 1-46.

DeRue, D. S., Nahrgang, J. D., Wellman, N., \& Humphrey, S. E. (2011). Trait and behavioral theories of leadership: An integration and meta-analytic test of their relative validity. Personnel Psychology, 64(1), 7-52.

Donaldson, T., \& Preston, L. E. (1995). The stakeholder theory of the corporation: Concepts, evidence, and implications. Academy of Management Review, 20(1), 65-91.

Duffy, M. K., Ganster, D. C., \& Pagon, M. (2002). Social undermining in the workplace. Acadademy of Management Journal., 45, 331-351.

Duxbury, L., \& Higgins, C. (2001). Work-Life balance in the new millennium: Where are we? Where do we need to go? Ottawa: Canadian Policy Research Networks.

Edwards, J. R., \& Lambert, L. S. (2007). Methods for integrating moderation and mediation: A general analytical framework using moderated path analysis. Psychological Methods, 12(1), 1-22.

Einarsen, S., Aasland, M. S., \& Skogstad, A. (2007). Destructive leadership behaviour: A definition and conceptual model. The Leadership Quarterly, 18(3), 207-216.

Eisenbeiss, S. A., \& Brodbeck, F. (2014). Ethical and unethical Leadership: A cross-cultural and cross-sectoral analysis. Journal of Business Ethics, 122(2), 343-359.

Festinger, L. (1957). A theory of cognitive dissonance. Palo Alto: Stanford University Press.

Golkar, A., Johansson, E., Kasahara, M., Osika, W., Perski, A., \& Savic, I. (2014). The influence of work-related chronic stress on the regulation of emotion and on functional connectivity in the brain. PloS One, 9(9), e104550.

Greenbaum, R. L., Mawritz, M. B., \& Piccolo, R. F. (2015). When leaders fail to "walk the talk" supervisor undermining and perceptions of leader hypocrisy. Journal of Management, 41(3), 929-956.

Guest, D. E. (2017). Human resource management and employee wellbeing: Towards a new analytic framework. Human Resource Management Journal, 27(1), 22-38.

Halbesleben, J. R. B. (2006). Sources of social support and burnout: A meta-analytic test of the conservation of resources model. Journal of Applied Psychology, 91(5), 1134-1145.

Halbesleben, J. R. B., \& Buckley, M. R. (2004). Burnout in organizational life. Journal of Management, 30(6), 859-879.

Hannah, S. T., Sumanth, J. J., Lester, P., \& Cavarretta, F. (2014). Debunking the false dichotomy of leadership idealism and pragmatism: Critical evaluation and support of newer genre leadership theories. Journal of Organizational Behavior, 35(5), 598-621.

Holden, L., Scuffham, P. A., Hilton, M. F., Ware, R. S., Vecchio, N., \& Whiteford, H. A. (2011). Health-related productivity losses increase when the health condition is co-morbid with psychological distress: Findings from a large cross-sectional sample of working Australians. BMC public health, 11(1), 417.
Hox, J. (2002). Multilevel analysis: Techniques and applications. Mahway: Lawrence Erlbaum Association Inc.

Hu, L., \& Bentler, P. M. (1999). Cutoff criteria for fit indexes in covariance structure analysis: Conventional criteria versus new alternatives. Structural Equation Modeling: A Multidisciplinary Journal, 6(1), 1-55.

Jackson, S. E., \& Schuler, R. S. (1985). A meta-analysis and conceptual critique of research on role ambiguity and role conflict in work settings. Organizational Behavior and Human Decision Processes, 36, 16-78. https://doi.org/10.1016/0749-5978(85)90020-2.

Johnson, J. V., \& Hall, E. M. (1988). Job strain, work place social support, and cardiovascular disease: A cross-sectional study of a random sample of the Swedish working population. American Journal of Public Health, 78(10), 1336-1342.

Johnson, R. E., Venus, M., Lanaj, K., Mao, C., \& Chang, C. H. (2012). Leader identity as an antecedent of the frequency and consistency of transformational, consideration, and abusive leadership behaviors. Journal of Applied Psychology, 97(6), 1262.

Kahn, R. L., Wolfe, D. M., Quinn, R. P., Snoek, D., \& Rosenthal, R. A. (1964). Organizational stress: Studies in role conflict and ambiguity. New York: Wiley.

Kalshoven, K., Den Hartog, D. N., \& De Hoogh, A. H. B. (2011). Ethical leadership at work questionnaire (ELW): Development and validation of a multidimensional measure. The Leadership Quarterly, 22(1), 51-69.

Karasek, R. A. (1979). Job demands, job decision latitude, and mental strain: Implications for job redesign. Administrative Science Quarterly, 24(2), 285-308.

Karasek, R. A. (1998). Demand/control model: A social, emotional, and physiological approach to stress risk and active behaviour development, in J. M. Stellman (Ed.), Encyclopaedia of occupational health and safety, (pp. 34.06-34.14), ILO, Geneva.

Karasek, R. A., \& Theorell, T. (1990). Healthy work: Stress, productivity, and the reconstruction of working life. New York: Basic Books.

Kline, T. (2005). Psychological testing: A practical approach to design and evaluation. Thousand Oaks: Sage.

Lanaj, K., Johnson, R. E., \& Lee, S. M. (2016). Benefits of transformational behaviors for leaders: A daily investigation of leader behaviors and need fulfillment. Journal of Applied Psychology, 101(2), 237

Lee, R. T., \& Ashforth, E. (1996). A meta-analytic examination of the correlates of the three dimensions of job burnout. Journal of Applied Psychology, 81(2), 123-133.

Lin, S. H. J., Ma, J., \& Johnson, R. E. (2016). When ethical leader behavior breaks bad: How ethical leader behavior can turn abusive via ego depletion and moral licensing. Journal of Applied Psychology, 101(6), 815.

Maslach, C. (1982). Burnout: The cost of caring. Englewood Cliffs: Prentice Hall.

Maslach, C., \& Jackson, S. E. (1981). The measurement of experienced burnout. Journal of Organizational Behavior, 2(2), 99-113.

Maslach, C., \& Jackson, S. E. (1984). Burnout in organizational settings. Applied Social Psychology Annual, 5, 133-153.

Maslach, C., \& Leiter, M. P. (2008). Early predictors of job burnout and engagement. Journal of Applied Psychology, 93(3), 498-512.

Maslach, C., Schaufeli, W. B., \& Leiter, M. P. (2001). Job burnout. Annual Review of Psychology, 52, 397-422.

Mayer, D. M., Nurmohamed, S., Treviño, L. K., Shapiro, D. L., \& Schminke, M. (2013). Encouraging employees to report unethical conduct internally: It takes a village. Organizational Behavior and Human Decision Processes, 121(1), 89-103.

Mo, S., \& Shi, J. (2017). Linking ethical leadership to employee burnout, workplace deviance and performance: Testing the mediating roles of trust in leader and surface acting. Journal of Business Ethics, 144(2), 293-303. 
Mulki, J. P., Jaramillo, F., \& Locander, W. B. (2006). Emotional exhaustion and organizational deviance: Can the right job and a leader's style make a difference? Journal of Business Research, 59(12), 1222-1230.

Mullen, J., Kelloway, E. K., \& Teed, M. (2011). Inconsistent style of leadership as a predictor of safety behaviour. Work \& Stress, 25(1), 41-54.

Nye, C. D., \& Drasgow, F. (2011). Effect size indices for analyses of measurement equivalence: Understanding the practical importance of differences between groups. Journal of Applied Psychology, 96(5), 966-980.

Preacher, K. J., Rucker, D. D., \& Hayes, A. F. (2007). Addressing moderated mediation hypotheses: Theory, methods, and prescriptions. Multivariate Behavioral Research, 42(1), 185-227.

Resick, C. J., Hanges, P. J., Dickson, M. W., \& Mitchelson, J. K. (2006). A cross-cultural examination of the endorsement of ethical leadership. Journal of Business Ethics, 63, 345-359.

Rizzo, J. R., House, R. J., \& Lirtzman, S. I. (1970). Role conflict and ambiguity in complex organizations. Administrative Science Quarterly, 15(2), 150-163.

Schaufeli, W. B., \& Bakker, A. B. (2004). Job demands, job resources, and their relationship with burnout and engagement: A multi-sample study. Journal of Organizational Behavior, 25(3), 293-315.

Schaufeli, W. B., \& Dierendonck, D. (2000). Utrechtse Burnout ScaleUBOS: Testmanual. Lisse: Swets \& Zeitlinger.

Schaufeli, W. B., Leiter, M. P., \& Maslach, C. (2009). Burnout: 35 years of research and practice. Career Development International, 14(3), 204-220.

Siegrist, J. (1996). Adverse health effects of high-effort/low-reward conditions. Journal of Occupational Health Psychology, 1(1), 27.

Skakon, J., Nielsen, K., Borg, V., \& Guzman, J. (2010). Are leaders' well-being, behaviours and style associated with the affective well-being of their employees? A systematic review of three decades of research. Work \& Stress, 24(2), 107-139.

Skogstad, A., Einarsen, S., Torsheim, T., Aasland, M. S., \& Hetland, H. (2007). The destructiveness of laissez-faire leadership behavior. Journal of Occupational Health Psychology, 12(1), 80-92.

Skogstad, A., Hetland, J., Glas $\varnothing$, L., \& Einarsen, S. (2014). Is avoidant leadership a root cause of subordinate stress? Longitudinal relationships between laissez-faire leadership and role ambiguity. Work \& Stress, 28(4), 323-341.

Steinmann, B., Nübold, A., \& Maier, G. W. (2016). Validation of a German version of the ethical leadership at Work Questionnaire by Kalshoven et al. (2011). Frontiers in Psychology, 7, 446.
Thau, S., Bennett, R. J., Mitchell, M. S., \& Marrs, M. B. (2009). How management style moderates the relationship between abusive supervision and workplace deviance: An uncertainty management theory perspective. Organizational Behavior and Human Decision Processes, 108(1), 79-92.

Treviño, L. K., Brown, M., \& Hartman, L. P. (2003). A qualitative investigation of perceived executive ethical leadership: Perceptions from inside and outside the executive suite. Human Relations, 56(200301), 5-37.

Van Veldhoven, M., \& Broersen, J. P. J. (1999). Psychosociale arbeidsbelasting en werkstress in Nederland. [Psychological job demands and job stress in the Netherlands. Amsterdam: Stichting Kwaliteitsbevordering Bedrijfsgezondheid.

Van Veldhoven, M., De Jonge, J., Broersen, S., Kompier, M., \& Meijman, T. F. (2002). Specific relationships between psychosocial job conditions and job-related stress: A three-level analytic approach. Work \& Stress, 16(3), 207-228.

Van Veldhoven, M., \& Meijman, T. F. (1994). Het meten van psychosociale arbeidsbelasting met een vragenlijst: de vragenlijst beleving en beoordeling van de arbeid (VBBA). [The measurement of psychosocial job demands with a questionnaire: The questionnaire on the experience and evaluation of work]. Amsterdam: Nederlands Instituut voor Arbeidsomstandigheden.

Walumba, F. O., \& Schaubroeck, J. (2009). Leader personality traits and employee voice behavior: Mediating roles of ethical leadership and work group psychological safety. Journal of Applied Psychology, 94(5), 1275-1286.

Welbourne, T. M., Johnson, D. E., \& Erez, A. (1998). The role-based performance scale: Validity analysis of a theory-based measure. The Academy of Management Journal, 41(5), 540-555.

Winter, D. G. (1991). A motivational model of leadership: Predicting long-term management success from TAT measures of power motivation and responsibility. The Leadership Quarterly, 2(2), $67-80$.

Xu, A. J., Loi, R., \& Lam, L. W. (2015). The bad boss takes it all: How abusive supervision and leader-member exchange interact to influence employee silence. The Leadership Quarterly, 26(5), $763-774$.

Zheng, D., Witt, L. A., Waite, E., David, E. M., van Driel, M., McDonald, D. P., Callison, K. R., \& Crepeau, L. J. (2015). Effects of ethical leadership on emotional exhaustion in high moral intensity situations. The Leadership Quarterly, 26(5), 732-748. 